\title{
A Progressive and Cell Non-Autonomous Increase in Striatal Neural Stem Cells in the Huntington's Disease R6/2 Mouse
}

\author{
Claudia M. C. Batista, ${ }^{1,2 *}$ Tod E. Kippin ${ }^{1,3 *}$ Sandrine Willaime-Morawek, ${ }^{1}$ Marília Kimie Shimabukuro, ${ }^{2}$ \\ Wado Akamatsu, ${ }^{1}$ and Derek van der Kooy ${ }^{1}$ \\ ${ }^{1}$ Neurobiology Research Group, Department of Medical Genetics and Microbiology, University of Toronto, Toronto, Ontario, Canada M5S 3E1, \\ ${ }^{2}$ Departmento de Histologia e Embriologia, Instituto de Ciências Biomédicas, Centro de Ciências da Saúde, Universidade Federal do Rio de Janeiro, 21941- \\ 590 Rio de Janeiro, Brazil, and '3Department of Psychology, University of California, Santa Barbara, Santa Barbara, California 93106-9660
}

Neural stem and progenitor cells are located in the subependyma of the adult forebrain. An increase in adult subependymal cell proliferation is reported after various kinds of brain injury. We demonstrate an expansion of neural precursor cells in the postnatal subependyma in a murine genetic disease model of Huntington's disease (HD), the R6/2 mouse. We used the in vitro neurosphere assay as an index of the number of neural stem cells in vivo and to assess proliferation kinetics in vitro and in vivo bromodeoxyuridine labeling to assess the progenitor cell population and their fates. Disease progression in this model leads to an increase in the numbers of neural stem cells in the adult striatal subependyma. This increase is produced cell non-autonomously by events in the R6/2 brains as the mice become increasingly symptomatic. Once the neural stem cell increase is induced in vivo, it is maintained during in vitro passaging of neural stem cells, but the neural stem cell increase is not reproduced during in vitro passaging of neural stem cells from presymptomatic R6/2 mice. In addition, we show that some of the R6/2 neural progenitor cells show a change from their normal migration destiny toward the olfactory bulb. Instead, some of these cells migrate into the striatum, one of the main affected areas in HD. Our findings demonstrate that HD damage recruits precursor cells in two ways: expansion of neural stem cells and altered migration of progenitor cells.

Key words: neural stem cells; progenitor cells; Huntington's disease; subependyma; migration; R/2 mice

\section{Introduction}

Stem cells (long-term self-renewing, multipotent precursors) and progenitor cells (renewal- and lineage-restricted precursors) reside in the adult ventricular subependyma and generate new neurons and glia in vivo (Weiss et al., 1996; Seaberg and van der Kooy, 2003). A major neurogenic system in the adult forebrain lies in the lateral ventricle subependyma, in which neural stem cells give rise to neuroblasts that migrate long distances to the olfactory bulb and differentiate into interneurons (Lois and Alvarez-Buylla, 1994). Increased proliferation in adult forebrain subependyma occurs in various brain injury models, including aspiration or transection lesions, inflammatory or chemical demyelination, and percussion trauma (Holmin et al., 1997; Calza et al., 1998; Jin et al., 2001; Parent et al., 2002). Moreover, stroke induces adult subependymal cells to proliferate and migrate in

Received Dec. 21, 2005; revised Aug. 28, 2006; accepted Aug. 29, 2006.

This work was supported by the Canadian Institute of Health Research, the Huntington's Disease Society of America, Stem Cell Network, the Regenerative Medicine Development Centre, the E. B. Eastburn Foundation, and a CAPES fellowship from the Brazilian government. We thank Dr. Anne Messer and Kevin Manley from the Wadsworth Center at the David Axelrod Institute (Albany, NY) and Dr. Harold Robertson from Dalhousie University (Halifax, Nova Scotia, (anada) for assistance in establishing the R6/2 mice colony and genotyping. We thank Brenda Coles for excellent technical assistance.

${ }^{*}$ C.M.C.B. and T.E.K. contributed equally to this work.

Correspondence should be addressed to Dr. Derek van der Kooy, Department of Medical Genetics and Microbiology, University of Toronto, 160 College Street, Centre for Cellular and Biomolecular Research, Room 1102, Toronto, Ontario, Canada M5S3E1.E-mail: derek.van.der.kooy@utoronto.ca.

DOI:10.1523/JNEUROSCI.2850-06.2006

Copyright $\odot 2006$ Society for Neuroscience ～0270-6474/06/2610452-09\$15.00/0 chain-like formations into the damaged striatum (Arvidsson et al., 2002). We sought to determine whether postnatal subependymal precursor cells undergo recruitment in a genetic disease model that causes forebrain deficits and, if so, then which type(s) of neural precursor cell (neural stem or neural progenitor cells) are primarily affected.

Huntington's disease (HD) is an inherited human neurodegenerative disorder resulting in neuronal cell death in discrete brain regions attributable to an expanded CAG repeat in the huntingtin gene (The Huntington's Disease Collaborative Research Group, 1993). The brain structures primarily affected in HD are the striatum and the cerebral cortex (for review, see Sathasivam et al., 1999). Because of the intimate proximity of the striatum to the adult subependyma, HD may potentially provide an optimal condition to investigate the ability of endogenous subependymal precursor cells to regenerate damaged cells in the adult CNS. The HD R6/2 mouse is a transgenic model of Huntington's disease in which there is cellular expression of exon 1 of the mutant (expanded CAG repeats) huntingtin gene. These transgenic mice appear to develop normally in the early postnatal period but display subtle deficits at 5-6 weeks of age, which progress to motor impairments analogous to those observed in HD by 9-12 weeks of age, with death occurring between 16 and 18 weeks (Mangiarini et al., 1996; Carter et al., 1999). An increased number of proliferating adult subependymal cells and new neurons are seen in the HD human brain, especially in patients with advanced HD (Curtis et al., 2003, 2005a,b). In con- 
trast, no changes in postnatal subependymal proliferation were seen in R6/2 mice, and, instead, an age-related decline in hippocampal neurogenesis is observed in this model compared with wild-type (WT) littermates (Gil et al., 2004; Phillips et al., 2005).

We now report that symptomatic HD R6/2 mice have an increased number of neural stem cells (NSCs) in the striatal subependyma as measured by the clonal neurosphere assay in vitro, along with in vivo immunohistochemical and electron microscopic analyses. Moreover, this increased number of NSCs is produced cell non-autonomously by events in the R6/2 brains as the mice become progressively symptomatic. Additionally, R6/2 neural progenitor cells display disrupted migration in vivo, and some are redirected away from the olfactory bulb into the damaged striatum.

\section{Materials and Methods}

Subjects. All mice were derived from heterozygous breeding of R6/2 $2^{+-}$ mice and their wild-type control strain (B6CBAF1/J), kindly provided by the laboratories of Dr. Anne Messer (Wadsworth Center at the David Axelrod Institute, Albany, NY) and Dr. Harold Robertson (Dalhousie University, Halifax, Nova Scotia, Canada). R6/2 mice possess an expanded exon 1 CAG repeat of the human HD gene (140-147) under control of the human IT15 promoter and recapitulate many of the features of human HD (Mangiarini et al., 1996; Carter et al., 1999; Lione et al., 1999).

Neurosphere assay. We used the in vitro neurosphere assay (Reynolds and Weiss, 1992; Morshead et al., 1994) to index the number of neural stem cells in vivo. Subsequently, the self-renewal and expansion characteristics of the neural stem cells in vitro were determined by serial passaging of neurospheres. The differentiation characteristics of neural stem cell progeny in vitro were determined by plating neurospheres in the presence of serum (Tropepe et al., 1999).

The subependyma of the lateral ventricle was dissected as described previously (Morshead et al., 1998). Subependymal tissue was subjected to enzymatic digestion $(1.33 \mathrm{mg} / \mathrm{ml}$ trypsin, $0.67 \mathrm{mg} / \mathrm{ml}$ hyaluronidase, and $0.2 \mathrm{mg} / \mathrm{ml} \mathrm{kynurenic} \mathrm{acid)} \mathrm{for} 50 \mathrm{~min}$ at $37^{\circ} \mathrm{C}$ and then isolated in serumfree media (SFM) with trypsin inhibitor. Tissue from all ages was mechanically dissociated into a single-cell suspension with a small-bore, fire-polished Pasteur pipette. Cell density and viability were determined using trypan blue exclusion.

Cells were cultured in the neurosphere assay under clonal conditions. Cells were plated at 10 cells $/ \mu \mathrm{l}$ in 24 -well $(0.5 \mathrm{ml} /$ well $)$ uncoated plates (Nunclon; Nunc, Naperville, IL) in serum-free medium containing 20 $\mathrm{ng} / \mathrm{ml}$ epidermal growth factor (mouse submaxillary; Sigma, St. Louis, $\mathrm{MO}$ ), $10 \mathrm{ng} / \mathrm{ml}$ fibroblast growth factor-2 (human recombinant, Sigma), and $2 \mu \mathrm{g} / \mathrm{ml}$ heparin (Upstate Biotechnology, Lake Placid, NY). Under these conditions, neurosphere colonies are derived from single cells and serve as an index of the number of in vivo neural stem cells (Morshead et al., 2003). The total number of spheres that formed in each well was counted after $7 \mathrm{~d}$.

To determine the self-renewal capacity, we mechanically dissociated spheres into single-cell suspensions either individually or in bulk and recultured them under the same conditions as primary cultures, and the number of neurospheres was determined after $7 \mathrm{~d}$. This was repeated at weekly intervals, and previous reports demonstrated that the neurospheres passaged up to 10 times (i.e., 10 weeks in vitro) are virtually identical to primary cultures (Reynolds and Weiss, 1996; Morshead et al., 2002).

To determine neuronal and glia differentiation of neural stem cell progeny in vitro, single spheres were differentiated in 24-well plates coated with Matrigel basement membrane matrix $(0.6 \mathrm{mg} / \mathrm{ml}$ in SFM; Becton Dickinson, Mountain View, CA) containing $0.5 \mathrm{ml}$ of SFM containing $1 \%$ fetal bovine serum (Invitrogen, Carlsbad, CA). Wells were processed $7 \mathrm{~d}$ later using immunocytochemistry as described previously (Tropepe et al., 1999).

Bromodeoxyuridine labeling, immunocytochemistry, and quantification. To index the total population of constitutively proliferating cells in the subependyma, mice were injected with bromodeoxyuridine (BrdU) $(60$ $\mathrm{mg} / \mathrm{kg}$, i.p., in saline; Sigma) every $3 \mathrm{~h}$ for a total of five injections and were killed $1 \mathrm{~h}$ after the final injection. To investigate the migration of BrdU-labeled neuroblasts along the rostral migratory stream into the olfactory bulb, animals were injected with BrdU and killed $7 \mathrm{~d}$ later. To examine the migration of BrdU-labeled neuroblasts into the striatum and the cerebral cortex, animals were injected with BrdU and killed $30 \mathrm{~d}$ later. In all cases, animals were overdosed with pentobarbital and perfused transcardially with PBS and 4\% paraformaldehyde. Brains were removed and postfixed overnight, cryoprotected with $30 \%$ sucrose in $\mathrm{PBS}$ at $4^{\circ} \mathrm{C}$, and then sectioned at $14 \mu \mathrm{m}$ thickness on a cryostat. Sections were incubated in $1 \mathrm{~N} \mathrm{HCl}$ at $60^{\circ} \mathrm{C}$ for $30 \mathrm{~min}$, then rinsed in PBS, and subsequently incubated in rat anti-BrdU antibody (1:100; Seralab, Crawley, UK) at $4^{\circ} \mathrm{C}$ overnight, followed by FITC donkey anti-rat antibody (1:200; Jackson ImmunoResearch, West Grove, PA) for $2 \mathrm{~h}$. The total number of BrdU-labeled cells in the subependyma was estimated using the optical dissector method (Coggeshall and Lekan, 1996) in sections randomly selected within the midportion of the anterior lateral ventricle. Numbers of BrdU-labeled cells in the granule cell layer (GCL) of the main olfactory bulb were determined in randomly selected sections extending $\sim 1 \mathrm{~mm}$ anterior to the rostral portion of the accessory olfactory. We also quantified numbers of labeled cells expressing endogenous markers of proliferating cells using the mouse monoclonal antiproliferating cellular nucleus antigen (PCNA) (1:200; Oncogene, Cambridge, MA) and migrating neuroblasts using the monoclonal antipolysialylated neural cell adhesion molecule (PSA-NCAM) (1:200; Chemicon, Temecula, CA), both visualized with Alexa Fluor 555 goat anti-mouse (1:400; Invitrogen). For double staining of BrdU and nestin, GFAP or neuronal-specific nuclear protein (NeuN), anti-nestin monoclonal (Chemicon), anti-GFAP monoclonal (DakoCytomation, High Wycombe, UK), and anti-NeuN monoclonal (Chemicon) were used in dilutions of 1:100, 1:1000, and 1:200, respectively. Alexa Fluor 568 secondary antibodies (Invitrogen) were used in a dilution of 1:300. Fluorescence was visualized using a Nikon (Tokyo, Japan) Microphot microscope or a Zeiss (Oberkochen, Germany) Apotome microscope.

BrdU labeling of neurosphere cultures was used to estimate the cell cycle time of neural progenitor cells, which make up the vast majority of cells in the neurospheres (Weiss et al., 1996). As described previously (Kippin et al., 2005a), neurospheres were prepared as above with the addition of $\mathrm{BrdU}(1 \mu \mathrm{M})$ during the last 1,6 , or $12 \mathrm{~h}$ of culturing (i.e., all cells harvested at the same time, $7 \mathrm{~d}$ after the start of the culture). After the prescribed BrdU exposure, neurospheres were collected in bulk, dissociated into single cells, plated onto Matrigel-coated plates in SFM without growth factors for $1 \mathrm{~h}$, fixed with $4 \%$ paraformaldehyde for $20 \mathrm{~min}$, and washed with PBS. Cells were stained using the same procedure as above and counterlabeled with Hoechst dye. The proportion of BrdU-labeled nuclei was determined for neurosphere cultures derived from separate animals in WT and HD groups.

Electron microscopy. R6/2 and WT mice $(n=3)$ were overdosed with pentobarbital and perfused transcardially with $0.9 \%$ saline, followed by $2 \%$ paraformaldehyde and $2.5 \%$ glutaraldehyde, for conventional electron microscopy (EM). The heads were removed and postfixed in the same fixative overnight. Then the brains were removed from the skull and washed in $0.1 \mathrm{~m}$ phosphate buffer for $2 \mathrm{~h}$. Sagittal $4 \mathrm{~mm}$ sections were cut with a razor blade. The sections were postfixed in $2 \%$ osmium for $2 \mathrm{~h}$, rinsed, dehydrated, and embedded in Epon (Electron Microscopy Sciences, Fort Washington, PA). For the identification of individual cell types, transverse ultrathin $(0.05 \mathrm{~mm})$ sections of the wall of the lateral ventricle were cut with a diamond knife, stained with lead citrate, and examined under a Jeol (Peabody, MA) 100CX electron microscope. The transverse ultrathin sections studied encompassed the entire anterior horn extent of the subependymal zone of the lateral ventricle. The classification of cell types was done as described previously (Doetsch et al., 1997).

Cell counts. The proportion of the different cell types in the subependymal zone of the wall of the lateral ventricle was estimated by counting the number of profiles corresponding to the different cell types along the dorsoventral extent of the subependymal zone at the electron microscope. This analysis was done only at the anterior horn level of the lateral 


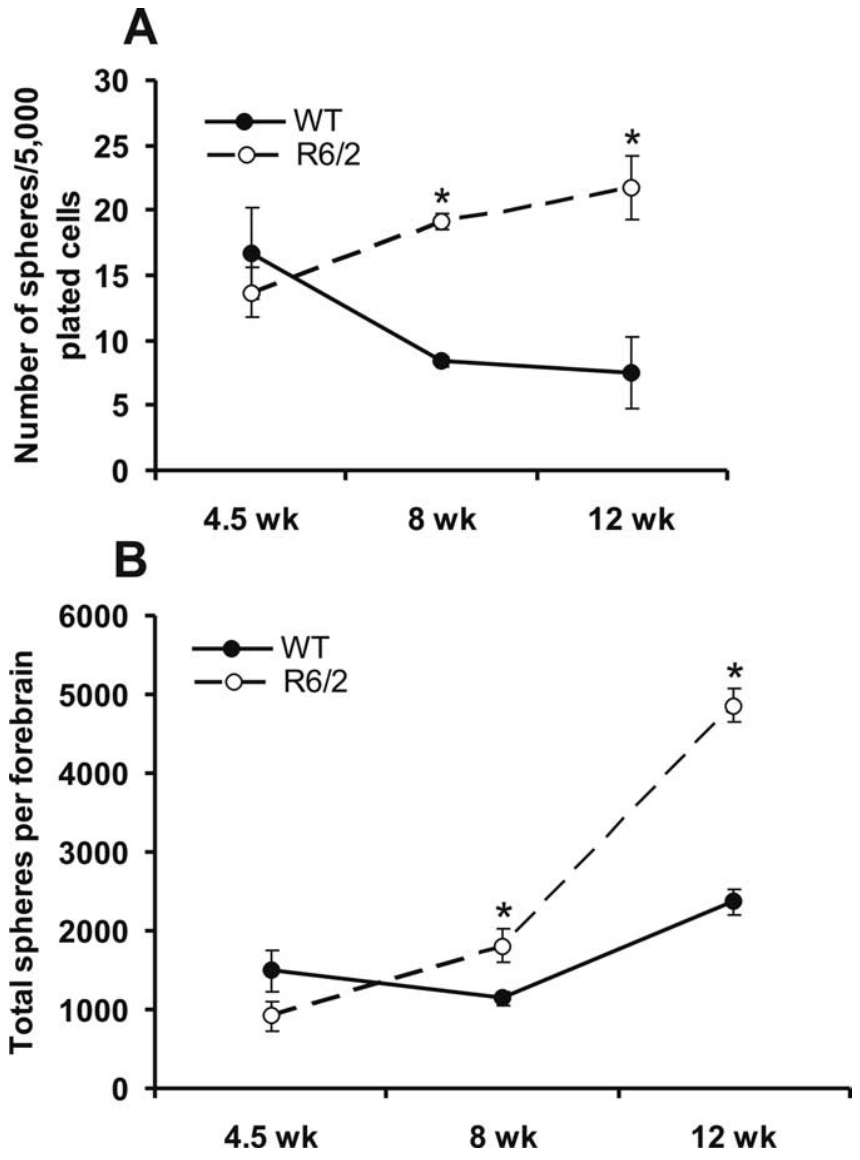

Figure 1. Subependymal stem cells increase progressively with the age of R6/2 mice compared with WT. $A$, Number of neurospheres per 5000 plated cells derived from the forebrain (lateral ventricle subependyma) from WT and R6/2 mice at $4.5,8$, and 12 weeks of age. $\boldsymbol{B}$, Total number of neurospheres per forebrain (from the lateral ventricle subependyma) derived in each condition. All data are expressed as mean \pm SEM. ${ }^{*} p<0.05$.

ventricle. The size, geometry, and orientation of the different cell types in the wall of the lateral ventricle and the number of profiles exposed in ultrathin electron microscopic sections is a fair representation of the composition of the subependymal zone (Doetsch et al., 1997).

Statistical analyses. Factorial design ANOVA, $t$ tests, or Mann-Whitney $U$ test were used to analyze data as appropriate (see below). Significant ANOVA values were followed by post hoc comparisons of individual means using the Tukey's method. The level of significance for all comparisons was 0.05 .

\section{Results}

Striatal subependymal neural stem cells increase progressively with the age of $\mathrm{R} 6 / 2$ animals

The in vitro neurosphere assay (Reynolds and Weiss, 1992; Morshead et al., 1994) was used to characterize the forebrain subependymal neural stem cell population of the R6/2 mouse, with the numbers of clonal neurospheres in vitro serving as a measure of the numbers of neural stem cells in vivo (Morshead et al., 1994, 1998). Relative to WT mice, the numbers of forebrain subependymal neurospheres initially are unchanged in asymptomatic R6/2 mice (at 4.5 weeks of age) (Fig. $1 A$ ). However, there is an interaction of age and strain at 8 and 12 weeks of age, when significantly more neurospheres can be derived from the R6/2 forebrain subependyma relative to $\mathrm{WT}\left(F_{(5,42)}=3.44 ; p<0.05\right)$. At 8 weeks of age, when R6/2 mice display behavioral deficits, such as irregular gait, stereotypic grooming movements, tremor, clasping, and tonic-clonic seizures (Sathasivam et al., 1999),

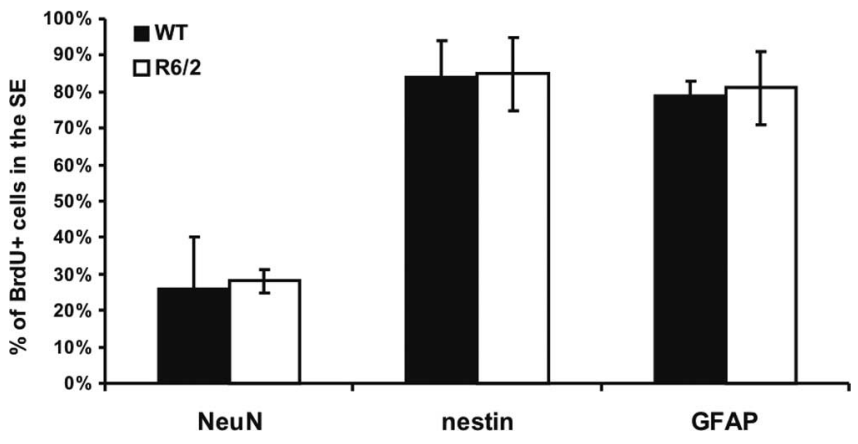

Figure 2. Phenotypes of BrdU-positive cells in the subependyma of WT and R6/2 mice. Specific markers were used to characterize BrdU ${ }^{+}$cells $30 \mathrm{~d}$ after BrdU injection. There were no significant differences between the percentages of BrdU ${ }^{+}$cells double labeled for $N e u N\left(t_{(3)}=\right.$ $0.109 ; p>0.05)$, nestin $\left(t_{(4)}=0.0707 ; p>0.05\right)$, or GFAP $\left(t_{(4)}=0.186 ; p>0.05\right)$ between WT and R6/2 mice. However, most of the BrdU-labeled cells were also nestin ${ }^{+}$and GFAP ${ }^{+}$, the typical neural stem cell phenotype.

there is an increase in the proportion of subependymal cells that form neurospheres relative to WT. At 12 weeks of age, when R6/2 mice are approaching the terminal point of this HD model, the proportion of subependymal cells that form neurospheres is increased threefold relative to WT. This increase in proportion of cells forming neurospheres may reflect either an increase in the absolute number of stem cells or a decrease in the proportion of non-stem cells in the region dissected (i.e., the number of neurospheres per well could go up without the stem cell population expanding if other cell types are decreasing). We therefore expressed the data as the total numbers of neurospheres per forebrain (Fig. $1 B$ ), which confirmed that R6/2 mice exhibit a progressive increase in the absolute numbers of neural stem cells in the striatal subependyma with significantly more neural stem cells at 8 and 12 weeks (but not 4.5 weeks) of age relative to age-matched WT controls $\left(F_{(5,83)}=43.96 ; p<0.05\right)$.

Long-term ( $30 \mathrm{~d})$ retention of BrdU labeling of NSCs in the subependyma in vivo confirmed the increase in NSC numbers in symptomatic R6/2 mice. Long-term retention of BrdU quantifies the proliferating portion of the relatively quiescent NSCs but not the rapidly dividing progenitors cells, which migrate out of the subependyma, undergo cell death, or dilute out the marker within 30 d (Morshead and van der Kooy, 1992; Luskin, 1993; Lois and Alvarez-Buylla, 1994; Morshead et al., 1998; Hitoshi et al., 2002). R6/2 and WT mice received a series of five BrdU injections over $12 \mathrm{~h}$ at 8 weeks of age and were killed $30 \mathrm{~d}$ later (at 12 weeks of age). R6/2 mice showed increased numbers of cells in the subependyma of the lateral ventricle that retained the BrdU label for $30 \mathrm{~d}$ relative to WT $\left(t_{(38)}=3.11, p<0.05 ; 4591 \pm 217\right.$ BrdU-labeled cells $/ \mathrm{mm}^{3}$ for the WT mice; for the R6/2 mice, $8393 \pm 138)$. These BrdU-positive $\left(\mathrm{BrdU}^{+}\right)$cells were later analyzed using specific markers. Figure 2 shows the percentage of $\mathrm{BrdU}^{+}$cells of different phenotypes in the subependyma, after $30 \mathrm{~d}$ of BrdU retention. Immunostaining showed that the percentages of $\mathrm{BrdU}^{+}$cells also positive for $\mathrm{NeuN}$, nestin, or GFAP are the same in WT and R6/2 mice (i.e., the relative cell fates do not change in the HD model). Given that $\sim 80 \%$ of the cells are $\mathrm{GFAP}^{+}$and $\sim 80 \%$ of the cells are nestin ${ }^{+}$, most cells must express both markers and thus are very likely to be stem cells. All double labeling of cells was confirmed with confocal microscope analyses. The total number of stained cells is $>100 \%$, but it is very unlikely that cells are staining for both neuronal (NeuN) and glial (GFAP) markers. Thus, we may have overestimated the numbers of GFAP and nestin cytoplasmic staining cells, because even with 

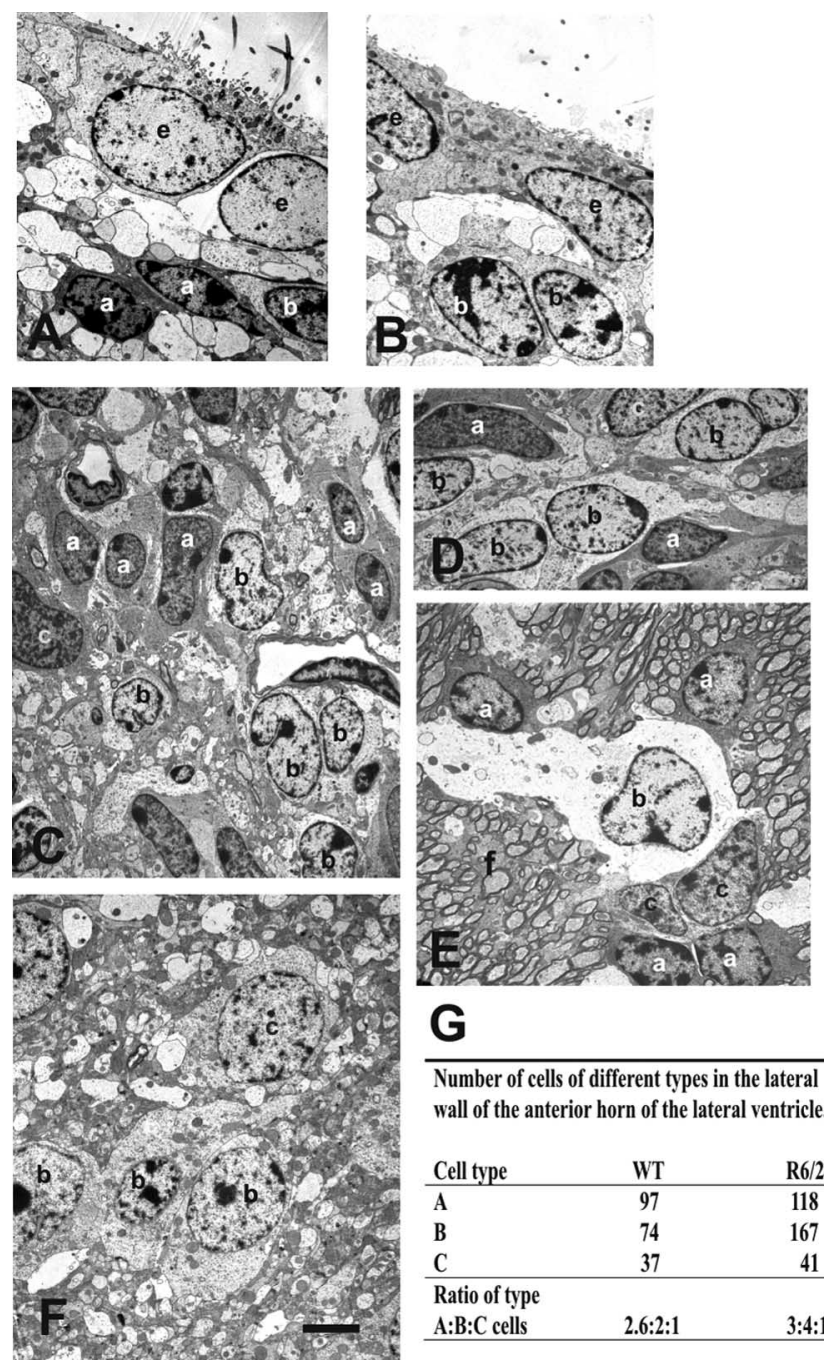

Number of cells of different types in the lateral wall of the anterior horn of the lateral ventricle.

\begin{tabular}{lcc} 
Cell type & WT & R6/2 \\
\hline A & 97 & 118 \\
B & 74 & 167 \\
C & 37 & 41 \\
\hline Ratio of type & & \\
A:B:C cells & $2.6: 2: 1$ & $3: 4: 1$ \\
\hline
\end{tabular}

Figure 3. Electron microscopy analysis show a specific increase number of $B$ cells (b) in the subependyma of the anterior horn of the lateral ventricle of the R6/2 mice. $A, B$, Typical ependymal and subependymal cells from the WT anterior horn of the lateral ventricle. $A(a)$ and $B$ cells are seen among cell processes. $C-F$, Subependymal cells from the same region in $R 6 / 2$ mice showing $A, B$, and $C$ (c) cell types. This subependyma is thicker compared with the WT one in $C$. In $\boldsymbol{D}$, a representative area with predominant $B$ cells. In $\boldsymbol{E}$, note the unusual location of the migratory $A$ cells with $B$ and C cells away from the lumen of the lateral ventricle, within the $R 6 / 2$ striatal fibers (f). $F, B$ and $C$ cells were also farther away from the lumen of the ventricle than in WT mice, among cell processes. $G$ shows the ratio of type $A / B / C$ cells in the subependyma of the anterior horn of the lateral ventricle in WT and R6/2 mice. e, Ependymal cells. Scale bar: $A, B, 1.8$ $\mu \mathrm{m} ; C, E, F, 1.6 \mu \mathrm{m}$.

confocal analyses, it is sometimes hard to tell how closely the cytoplasmic staining marks the same cell as the nuclear BrdU staining.

\section{EM-defined B cells are increased in the R6/2 subependyma}

To better characterize the cells in the R6/2 subependyma compared with WT, subependymal tissue was processed for EM. The morphology of A cells (Fig. 3A) were identified by an elongated cell body with one or two processes, abundant lax chromatin with two to four small nucleoli, and dark cytoplasm (Doetsch et al., 1997). Type B cells (Fig. 3B) had irregular contours that profusely filled the spaces between neighboring cells. These cells had irregular nuclei that frequently contained invaginations (Fig. $3 C$ ). The cytoplasm of type B cells was light. Salient characteristics of type $\mathrm{B}$ cells were also their dense bodies in the cytoplasm. Some type B cells were common adjacent to ependymal cells, in which they extended many processes to form a lamina covering the ependymal layer. In some cases, these type B cells were localized most frequently at the interface with the striatal parenchyma. Type $\mathrm{C}$ cells (Fig. 3C,F) differed from both type A cells (putative migrating cells) and type B cells (astrocytes). Type C cells were larger, more spherical (less elongated), and more electron-lucent than type A cells but more electron-dense than type B cells.

WT subependyma comprised five to six layers of cells (Doetsch et al., 1997). R6/2 brains, in contrast, appeared to have an expanded subependymal width. Another distinct feature was the location of some of the migratory A cells along with B and C cells farther from the lumen of the lateral ventricle in the R6/2 ( 150-200 $\mu \mathrm{m}$ away from ependymal cells) compared with WT mice. The ratio of type $\mathrm{A} / \mathrm{B} / \mathrm{C}$ cells in WT subependyma was 2.6:2:1 (Fig. 3G), very close to the previously described ratio of 3:2:1 (Doetsch et al., 1997). Conversely, the ratio type of A/B/C cells in R6/2 subependyma was 3:4:1, showing that B cells are at least twofold increased in HD mouse model, whereas A and C cells showed only small changes in these ratios comparing WT and $\mathrm{R} 6 / 2$ mice.

\section{R6/2 neural stem cells maintain greater self-renewal during passaging in vitro compared with WT}

To investigate self-renewal characteristics of R6/2 striatal subependymal neural stem cells, primary spheres were individually dissociated into single cells and replated in identical media conditions. Through the use of this passaging assay, self-renewal ability is assessed by the formation of clonally derived secondary sphere colonies. The number of spheres that form at each passage is a measure of the number of times the primary sphere-initiating cell has symmetrically divided in vitro (Reynolds and Weiss, 1996; Hitoshi et al., 2002). When we performed single-sphere passaging of primary spheres derived from R6/2 and WT mice at 12 weeks of age, we found that R6/2 subependymal stem cells display greater expansionary self-renewal compared with WT spheres $t_{(47)}=2.36, p<0.05 ; 6.30 \pm 8.51$ secondary spheres per primary colony for the WT mice; $33.98 \pm 19.10$ for the R6/2 mice). WT and R6/2 primary spheres were not significantly different in diameter, suggesting that the primary sphere progenitor cells did not differ between WT and R6/2.

The self-renewal capacity of neural stem cells also was analyzed through bulk passaging of neurosphere cultures (Fig. 4A). R6/2 and WT neurospheres were mechanically dissociated into single-cell suspension in bulk and recultured under the same conditions as primary cultures, and the numbers of neurospheres were counted after $7 \mathrm{~d}$. Bulk passaging (Fig. 4A) also revealed increased stem cell symmetric divisions in cultures from R6/2 mice at 12 weeks of age relative to WT during serial passaging $\left(F_{(5,203)}=54.26 ; p<0.05\right)$, with increased numbers of neurospheres in both secondary and tertiary R6/2 cultures relative to WT. These findings demonstrate that the increase in symmetric divisions once induced is intrinsically maintained by R6/2 stem cells across multiple passaging in vitro, suggesting that the increase in stem cells observed in vivo (Fig. $1 A, B$ ) is attributable to some factor reprogramming stem cells to undergo symmetric divisions during HD progression.

\section{The increase in self-renewal is induced cell non- autonomously in $\mathrm{R} 6 / 2$ forebrain stem cells} Given that, once the age-dependent increase in R6/2 stem cell symmetric division is induced and it can be maintained in vitro, we hypothesized that, if the enhancement of self-renewal in R6/2 

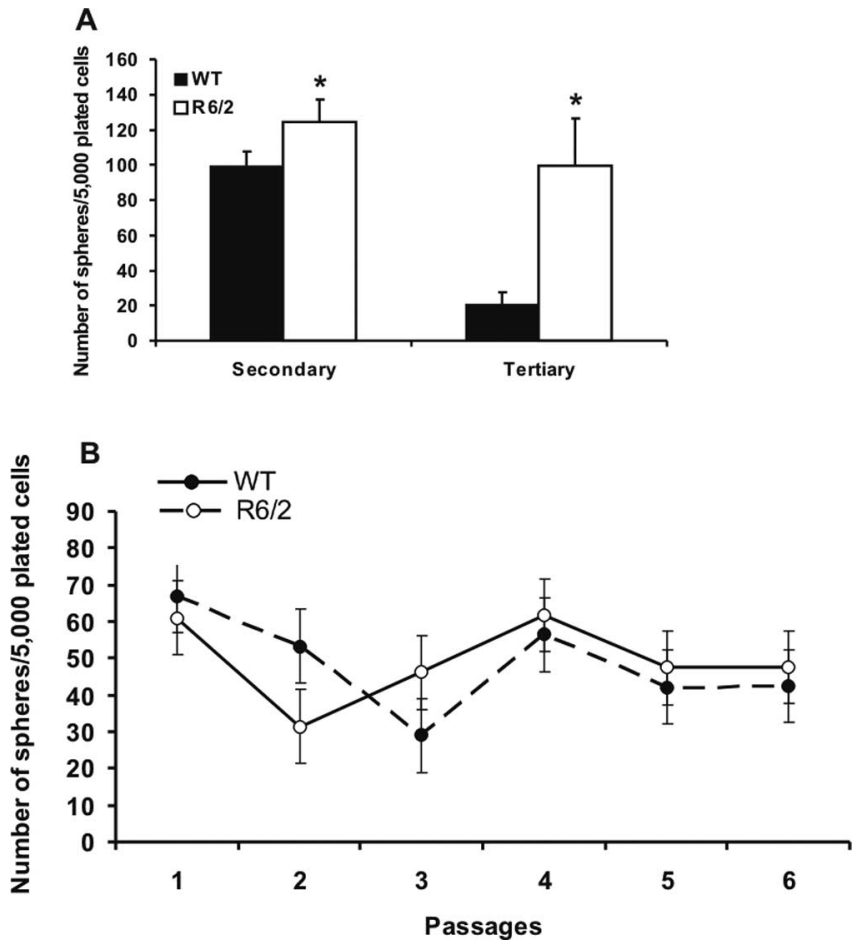

Figure 4. Forebrain stem cells from symptomatic R6/2 mice display enhanced self-renewal induced cell non-autonomously in the $R 6 / 2$ brain, but, once induced, this enhanced selfrenewal is maintained in vitro. $A$, Serial bulk passaging of neurosphere colonies from symptomatic, 12-week-old R6/2 and WT mice forebrains. Bulk passages were performed every 7 d. $\boldsymbol{B}$, Bulk passages of neurosphere colonies from presymptomatic R6/2 and WT mice (at 4.5 weeks of age) over 6 weeks yields equivalent numbers of neural stem cells. All data are expressed as mean \pm SEM. ${ }^{*} p<0.05$.

stem cell is mediated cell autonomously, then we should be able to reproduce this effect during serial passaging of R6/2 stem cells derived from presymptomatic mice. As indicated in Figure 1, $A$ and $B$, asymptomatic R6/2 mice (at 4.5 weeks of age) have similar numbers of neurosphere-forming cells as WT mice in vivo. After serial bulk passaging of neurosphere cultures derived from mice at 4.5 weeks of age for a period of 6 weeks (comparable with primary neurospheres derived from mice at 10.5 weeks of age), the numbers of clonal neurospheres remained similar in R6/2 and WT cultures (Fig. $4 B)\left(F_{(13,115)}=1.83 ; p>0.05\right)$. Thus, the production of more clonal primary neurospheres seen at the symptomatic older ages (e.g., 8 weeks and beyond) in R6/2 compared with WT mice (Figs. $1 A, B, 4 A$ ) is not acquired during passaging in vitro over a similar time period during which an increase in neural stem cells is seen in vivo in the R6/2 forebrain. Together, these findings suggest two conclusions. First, the increase in neural stem cell numbers and self-renewal is induced cell non-autonomously by the in vivo R6/2 host brain. Second, once induced in vivo, this potentiated self-renewal effect is maintained cell autonomously in vitro.

To determine multipotentiality of R6/2 and WT primary clonal neurospheres, single spheres (from 12 weeks of age mice) were differentiated in 24-well plates coated with Matrigel basement membrane matrix containing the standard media plus $1 \%$ fetal bovine serum. Wells were processed $7 \mathrm{~d}$ later using immunocytochemistry for $\beta$ III-tubulin (neurons), GFAP (astrocytes), or O4 (oligodendrocytes). R6/2 and WT spheres generated equivalent proportions of neurons $(6.3 \pm 1.6$ and $5.7 \pm 1.2$, respectively), astrocytes $(90.3 \pm 11.7$ and $91.2 \pm 10.4$, respectively), and oligodendrocytes $(2.9 \pm 0.8$ and $3.1 \pm 0.7$, respectively $)(F<1.0$;

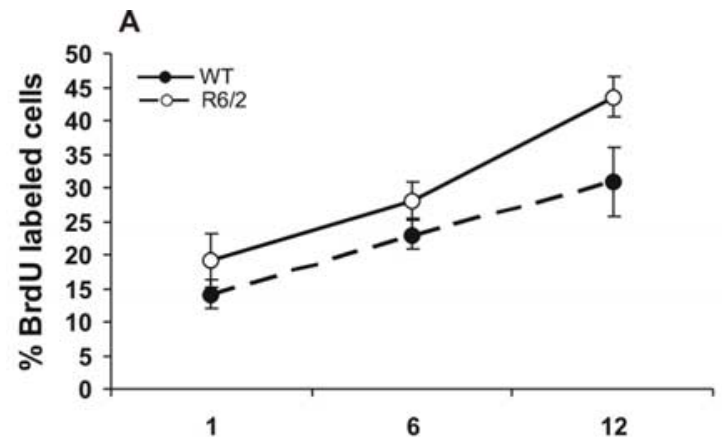

Hours of exposure
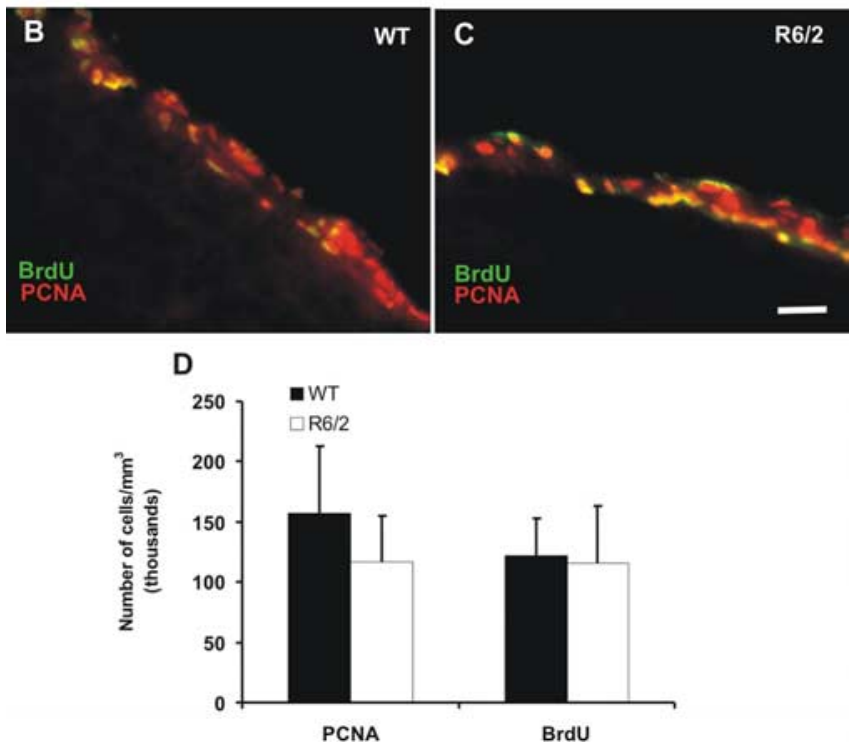

Figure 5. The increase in forebrain neural stem cells does not affect progenitor cells in the adult forebrain subependyma in R6/2 mice. $A$, Cumulative BrdU labeling of primary neurosphere cultures from WT and R6/2 mice subependyma at 12 weeks of age. Neurosphere cultures from R6/2 do not incorporate BrdU faster than neurospheres from WT littermates in vitro. $\boldsymbol{B}, \boldsymbol{C}$, Photomicrographs of neural progenitor cells from symptomatic R6/2 (12 weeks of age) and their WT littermate forebrain controls in vivo immunolabeled with PCNA and BrdU on the same slide sections to confirm the same levels of labeling for both markers. $D$, There was no difference in the total numbers of PCNA- or BrdU-labeled cells between R6/2 and WT littermate controls. All data are expressed as mean \pm SEM. Scale bar: $B, C, 80 \mu \mathrm{m}$.

$p>0.05)$. Thus, the potentiated self-renewal of forebrain stem cells associated with onset of HD symptoms is not associated with changes in multipotentiality in R6/2 mice.

The increase in forebrain neural stem cells does not affect neural progenitor cells in the adult forebrain striatal subependyma in $\mathrm{R} 6 / 2$ mice in vitro or in vivo

Next, we examined the effect of mutant huntingtin on the constitutively proliferating progenitor cells in the subependyma of symptomatic R6/2 mice. Because these progenitor cells make up the vast majority of cells in the neurospheres (Reynolds and Weiss, 1996), we determined their proliferation kinetics using incorporation of BrdU in R6/2 and WT neurosphere cultures. Cumulative BrdU labeling of primary neurosphere cultures from the subependyma of WT and R6/2 mice at 12 weeks of age revealed no significant difference in the proliferation of $\mathrm{R} 6 / 2$ and WT progenitor cells in vitro (Fig. $5 A$ ). There was a significant effect of time of BrdU exposure $\left(F_{(5,56)}=8.47 ; p<0.05\right)$, with higher numbers of BrdU-labeled cells after $12 \mathrm{~h}$ of exposure (for 

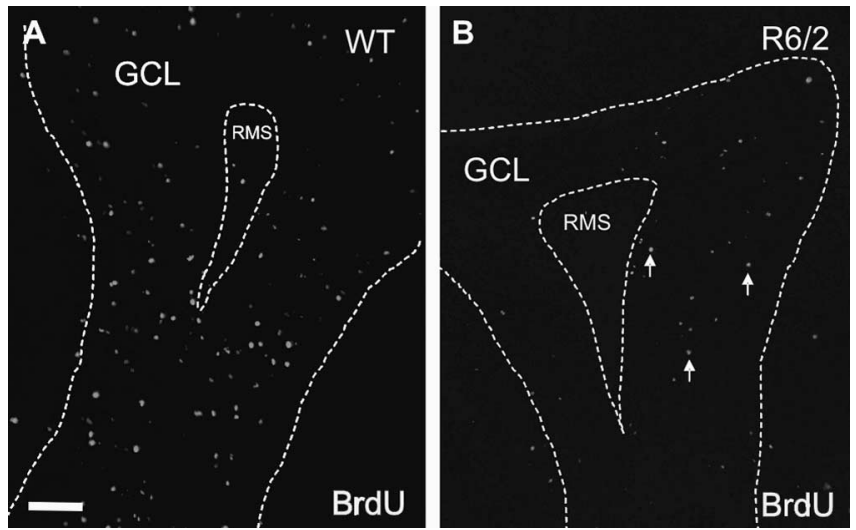

Figure 6. R6/2 progenitor cells have a deficit in migration to the olfactory bulb. $A, B$, Representative sections of BrdU-labeled cells in the GCL of the olfactory bulb in both R6/2 and WT mice at 13 weeks of age ( $7 \mathrm{~d}$ survival). Animals were killed $7 \mathrm{~d}$ after BrdU injections. All data are expressed as mean \pm SEM. Scale bar, $100 \mu \mathrm{m} .{ }^{*} p<0.05$. RMS, Rostral migratory stream.

both R6/2 and WT) than at shorter exposures ( 1 and $6 \mathrm{~h}$ of exposure) but no significant interaction between genotype and time of exposure or effect of genotype.

To estimate the entire constitutively proliferating progenitor cell population in the adult R6/2 forebrain striatal subependyma in vivo, we injected BrdU every $3 \mathrm{~h}$ for $15 \mathrm{~h}$ to cover the entire cell cycle time of the constitutively proliferating progenitor cells (Morshead and van der Kooy, 1992; Morshead et al., 1994, 1998). We found no difference in the total numbers of BrdU-labeled cells in the subependyma between symptomatic R6/2 (12 weeks of age) and their WT littermate controls in vivo (Fig. $5 B-D$ ). Similarly, immunostaining against PCNA revealed similar numbers of labeled cells in the subependyma of R6/2 and WT brains $\left(F_{(3,32)}=0.278 ; p>0.05\right)$. Additionally, quantification of BrdUlabeled cells in the subependyma $1 \mathrm{~h}$ after a single injection of BrdU also failed to detect differences between symptomatic R6/2 and WT progenitor cell populations. These data suggest that there is no effect on progenitor cell population in the R6/2 adult forebrain subependyma in vivo.

\section{$\mathrm{R} 6 / 2$ progenitors have a deficit in migration to the olfactory bulb and are redirected to the striatum}

To ask whether the expanded neural stem cell population in the R6/2 mouse subependyma has consequences for one of the primary fates of these cells (the production of new adult olfactory bulb interneurons), mice at 12 weeks of age were injected with BrdU and killed $7 \mathrm{~d}$ later, when many of the BrdU-positive cells are expected to be in the GCL of the main olfactory bulb (Lois and Alvarez-Buylla, 1994; Craig et al., 1999). We observed significantly lower densities of BrdU-positive cells in the GCL of the $\mathrm{R} 6 / 2$ mice relative to $\mathrm{WT}\left(t_{(4)}=-3.43, p<0.05 ; 12,638 \pm 3520\right.$ BrdU-labeled cells $/ \mathrm{mm}^{3}$ for the WT mice; for the R6/2 mice, $3193 \pm 689$ ) (Fig. 6A,B).

Given this neurogenesis deficiency in the R6/2 olfactory bulb, we evaluated more accurately possible alternative migratory fates of subependymal precursors. Specifically, we hypothesized that, if precursors cells show a change in their migration destiny to the olfactory bulb in symptomatic mice ( 12 weeks of age), then these cells might be migrating to brain areas affected by HD pathology, such as the striatum or cortex in an attempt to compensate the local cell losses. Accordingly, R6/2 and WT mice at 10 weeks of age were injected with BrdU and killed $30 \mathrm{~d}$ later. Analyses of the striatum adjacent to the lateral ventricle (up to $100 \mu \mathrm{m}$ from the subependyma) revealed more BrdU-positive cells in the striatum in $\mathrm{R} 6 / 2$ mice relative to WT $\left(t_{(7)}=-4.44, p<0.05 ; 66.41 \pm\right.$ $39.81 \mathrm{BrdU}$-labeled cells $/ \mathrm{mm}^{3}$ for the WT mice and $871.9 \pm 157$ for the R6/2 mice). Furthermore, $\sim 10 \%$ of the BrdU-labeled cells also expressed PSA-NCAM (Fig. 7A-C), suggesting that they are migrating neuroblasts, perhaps redirected away from the normal migratory pathway to the olfactory bulb in an attempt to compensate for the cell loss in the striatum. In contrast, we did not observe a significant difference in BrdU-labeled cells in the cerebral cortex of R6/2 relative to WT at the same age (Mann-Whitney $U$ test, $Z=0.894 ; p=0.371$ ).

To analyze the potential different phenotypes of the long-term survival, BrdU-positive cells in the striatum, we performed immunostaining and quantified cells double labeled for NeuN, nestin, or GFAP. The relative percentages of BrdU double-labeled cells in the WT versus R6/2 postmitotic striatal tissue were not significantly different $\left(t_{(4)}=1.015 ; p>0.05\right)$. Nevertheless, there was a tendency for a decrease in the percentage of $\mathrm{BrdU}^{+}$cells that were also $\mathrm{GFAP}^{+}$in the R6/2 compared with WT striatum, i.e., the absolute number of new astrocytes are decreased in R6/2 (Fig. 8). Conversely, the percentage of $\mathrm{BrdU}^{+}$striatal cells that were double labeled for NeuN showed a nonsignificant increase $\left(t_{5}=1.188 ; p>0.05\right)$ in the R6/2 compared with WT striatum with a tendency of more new neurons in R6/2 (Fig. 8). Most of the increased R6/2 cell types within the subependyma are nestin ${ }^{+}$ and $\mathrm{GFAP}^{+}$double-labeled cells (Fig. 2), which suggests that these cells are neural stem cells. However, some of these subependymal cells may also be postmitotic reactive astrocytes. We found no significant increases in the relative percentages of $\mathrm{BrdU}^{+}$cells that are neurons or glia within the R6/2 compared with WT striatum itself. Nevertheless, because there are more $\mathrm{BrdU}^{+}$cells in the $\mathrm{R} 6 / 2$ than WT postmitotic striatum $\left(\mathrm{BrdU}^{+}\right.$ cells after $30 \mathrm{~d}$ of survival), then there certainly are absolutely more neurons and glial cells in the R6/2 striatum, including approximately five times more astrocytes in R6/2 compared with WT. Thus, more stem cells may have produced absolutely more striatal astrocytes after $30 \mathrm{~d}$ of survival. Moreover, some of the astrocyte progenitors already in the striatum also may have accounted for some of the five times increase in the number of astrocytes in R6/2 compared with wild-type striatum.

Although we observed a 10 -fold increase in the number of 30 -d-survival BrdU ${ }^{+}$cells in the R6/2 compared with WT striatum $\left(\mathrm{BrdU}^{+}\right.$cells in the lateral ventricle after $30 \mathrm{~d}$ of survival), only approximately one-half of the BrdU-positive cells $30 \mathrm{~d}$ after BrdU injection, in both R6/2 and WT mice, were double labeled with NeuN, nestin, or GFAP. One possibility to explain this result is that some of these $\mathrm{BrdU}^{+}$cells in the striatum might be endothelial cells or blood-derived cells. Another possibility is that some of the new cells in the R6/2 and WT striatum might be other cell types generated from NSCs (oligodendrocytes or nestin ${ }^{-}$/ $\mathrm{NeuN}^{-}$young neuron) that were not sampled here.

\section{Discussion}

The present study demonstrates that forebrain neural precursor cells are activated in a murine transgenic model of HD. The onset of motor symptoms in the R6/2 mouse is accompanied by a progressive increase in numbers of forebrain stem cells in the striatal subependyma. This increase in forebrain neural stem cells was demonstrated in three separate assays: a increased number of clonal neurospheres in vitro from the R6/2 mice, an increased number of BrdU ${ }^{+}$label retaining cells ( $30 \mathrm{~d}$ after BrdU injection) in the R6/2 subependyma in vivo (cells that expressed both nestin and GFAP, further suggesting their stem cell identity), and finally 
an increased number of type B cells in the R6/2 subependyma at the EM level. Moreover, R6/2 stem cells from symptomatic, but not presymptomatic, mice exhibit potentiated self-renewal during serial passaging in vitro (i.e., the effect occurs only in vivo but persists in vitro), suggesting that the potentiated self-renewal of stem cells is induced by cell non-autonomous factors in the neurodegenerative brain but is maintained cell autonomously once it is induced. Furthermore, the effect is specific to stem cells because the numbers of progenitors cells are not influenced either in vitro or in vivo. The adult subependyma consists of at least two kinetically distinct cell populations: a relatively quiescent stem cell population and a constitutively proliferating progenitor cell population (Morshead et al., 1994). The postmitotic fate of the constitutively proliferating cell population has been determined to be cell death or neuronal differentiation and migration to the olfactory bulb (Morshead and van der Kooy, 1992; Lois and Alvarez-Buylla, 1994). The present results demonstrate a gradual increase in the numbers of striatal neural stem cells that correlates with symptomatic disease progression. Furthermore, this increased expansion was maintained (once induced) but was not induced during in vitro passaging of clonal neurosphere cultures from presymptomatic R6/2 mice. These findings imply that the progression of the disease in the host brain cell nonautonomously induces symmetrical divisions in the neural stem cell population in vivo. In contrast, the progenitor cell population did not appear to be altered during the onset of R6/2 symptoms. No differences were detected in the total numbers of neural progenitor cells between symptomatic R6/2 and their WT controls in vivo as measured by either BrdU and PCNA immunostaining (nor in their neuronal or glial phenotypes), which is consistent with the findings of other recent reports (Gil et al., 2004; Phillips et al., 2005). Furthermore, despite increased neural stem cell symmetric divisions, neurosphere cultures from R6/2 forebrain do not incorporate BrdU faster than neurospheres cultured cells from WT in vitro. Given that neural stem cell proliferation predominantly gives rise to progenitor cells via asymmetric cell divisions in vivo, it is surprising that the increased numbers of forebrain stem cells in the R6/2 brain does not produce an indirect increase in the numbers of their neural progenitor progeny. Hence, the symptomatic R6/2 brain may produce an environment in which either stem cells may be inhibited in their ability to make asymmetric divisions (perhaps attributable to reprogramming toward symmetric divisions) or there may be altered survival and migratory kinetics of progenitor cells out of the subependyma counteracting increases in stem cell proliferation, or a combination of these factors.

The potential growth factors in the HD striatum that might be associated with the increased neural stem cell self-renewal remain unknown. However, endothelial cells have fundamental roles in neurogenic niches. Progenitor cells are found in close proximity to the tips of capillaries, and NSCs in the subependyma lie adjacent to the ependymal layer that lines the lateral ventricles and the blood vessels (Palmer et al., 2000; Ramírez-Castillejo et al., 2006). Furthermore, vasculature-secreted factors promote precursor cell proliferation and/or survival (Jin et al., 2002). Blood-borne inflammatory signals also are counteracted by endogenous antiinflammatory factors such as pigment epithelium-derived factor

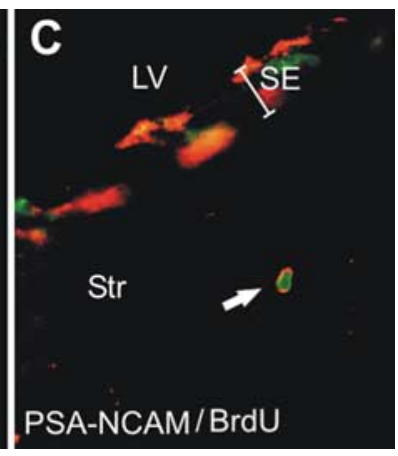

PSA-NCAM/BrdU
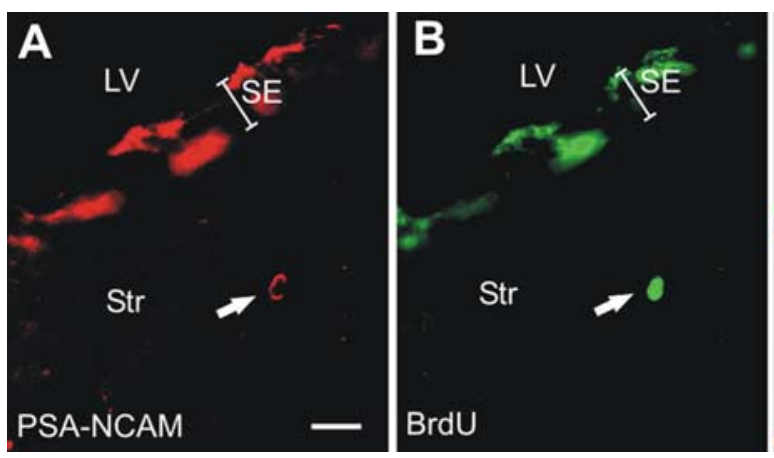

Figure 7. R6/2 progenitor cells are redirected into the striatum. $\boldsymbol{A}-\boldsymbol{C}$, Representative section showing one double-labeled (arrow) PSA-NCAM (A) and BrdU (B) cell in the striatum of an R6/2 mouse at 13 weeks of age ( $7 \mathrm{~d}$ survival). $\boldsymbol{C}$, Merged images. LV, Lateral ventricle; Str, striatum; SE, subependyma. Scale bar, $10 \mu \mathrm{m}$.

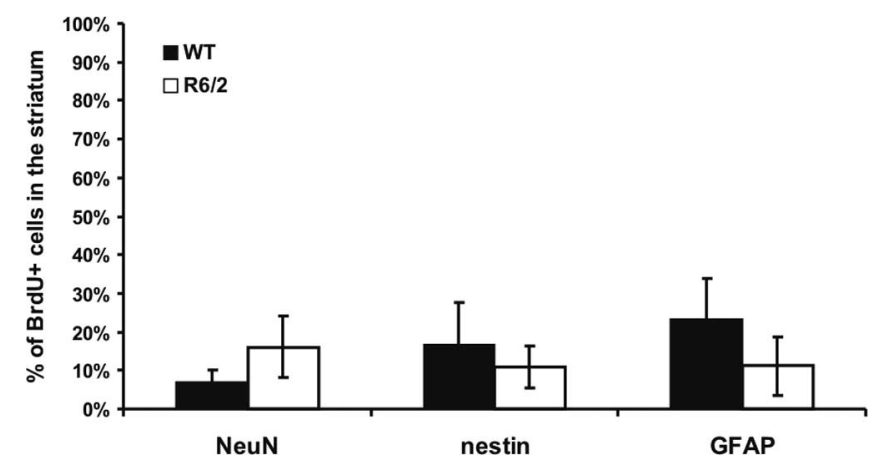

Figure 8. Phenotypes of BrdU-positive cells in the striatum of WT and R6/2 mice. Specific markers were used to characterize BrdU ${ }^{+}$cells $30 \mathrm{~d}$ after BrdU injection. There is a nonsignificant $\left(t_{(5)}=1.188 ; p>0.05\right)$ tendency for the $\mathrm{R} 6 / 2$ striatum to have a greater percentage of $\mathrm{BrdU}^{+}$neurons (NeuN ${ }^{+}$cells). The percentage of BrdU ${ }^{+}$cells double labeled for GFAP in the R6/2 mice does not show a relative astrocytosis in the striatum compared with WT mice, but, given the greater number of BrdU ${ }^{+}$cells, there are absolutely more astrocytes in the R6/2 striatum.

(PEDF) (Zhang et al., 2006). PEDF is elevated in CSF of patients with amyotrophic lateral sclerosis (Kuncl et al., 2002) and in patients with Alzheimer's disease (Castano et al., 2006). PEDF recently was suggested as a niche signal for neural stem cell renewal (Ramírez-Castillejo et al., 2006). PEDF is the first soluble factor known to activate B cells specifically, and factors such as PEDF are viable candidate mediators of the effects on neural stem cells in the HD brain. Conversely, dopamine specifically inhibits neural stem cell proliferation (Kippin et al., 2005b), and striatal dopamine levels are decreased in symptomatic R6/2 (Hickey et al., 2002) and R6/1 (Petersen et al., 2002; Pineda et al., 2005), suggesting that loss of tonic dopaminergic inhibition of stem cell proliferation also could mediate some of the effects seen in the R6/2 subependyma.

Remarkably, light microscopic, cytoarchitectural analyses of human HD subependyma revealed increased numbers of type B cells (putative stem cells), with no significant increase in the numbers of type A and C cells (putative progenitors cells) (Curtis et al., 2005b). Similar increases in type B cells were seen in the R6/2 subependyma in the present report. Furthermore, the increases in stem cells in HD patients correlated with advancement of HD symptoms (Curtis et al., 2005a). Thus, in both the human and the mouse brain, expanded CAG repeat pathology appears to induce a specific increase in forebrain stem cells. Our present data demonstrate that these increases in stem cells are mediated through the ability of the microenvironment of the HD brain to 
cell non-autonomously induce stem cells to make more symmetric divisions.

The second main effect on neural precursors seen in the symptomatic R6/2 brain is the decreased number of neuroblasts migrating to their normal targets in the olfactory bulb and the increased number of neural precursors migrating into the striatum. Examination of BrdU-labeled cells in the striatum after shortterm survival in 12 week R6/2 mice revealed no increase in the number of BrdU-labeled cells, whereas significantly more BrdUlabeled cells were seen in the striatum at $30 \mathrm{~d}$. Although the relative proportions of neurons to astroglial cells were similar in WT and R6/2 striatum, the absolute increases in new cells in the R6/2 striatum $30 \mathrm{~d}$ after BrdU means that absolutely more new neurons and new glial cells were populating the R6/2 striatum. Neuronal loss has not been reported in the R6/2 striatum. It is reasonable to suggest that the absolute increase in new neurons that we see in the R6/2 striatum may hide a small loss of old neurons in this structure. Other new ( $30 \mathrm{~d}$ after $\mathrm{BrdU}^{+}$) R6/2 striatal cells are apparently non-neuronal and non-astroglial. This suggests that the HD pathology might encourage the proliferation of other cell types such as endothelial cells or oligodendrocytes in the HD striatum. However, microglia density is decreased by 7 weeks of age in R6/2 mice (Ma et al., 2003), suggesting that the BrdUlabeled cells migrating into the striatum are unlikely to include many microglial cells.

Neuroblast migration along the rostral migratory stream is precisely regulated by cooperation between several repellants, attractants, guidance, and trophic molecules located within specific brain regions. Infusion of BDNF into or viral-induced BDNF overexpression in the lateral ventricles of adult rats can substantially increase the number of newly generated neurons in the olfactory bulb and the striatum (Zigova et al., 1998; Benraiss et al., 2001; Chmielnicki et al., 2004). The reduced migration to the olfactory bulb may reflect reduced levels of BDNF reported in R6/2 mouse brains (Saudou et al., 1998; Zuccato et al., 2005).

The present report quantitates the longer-term (30 d after BrdU injection) fates of the new cells in the R6/2 and wild-type striatum. We show that there are more absolute $\mathrm{BrdU}^{+}$cells that survive in the R6/2 compared with wild-type striatum. However, the relative proportions of new neurons and new glial do not change significantly between the R6/2 versus wild-type striatum. Nevertheless, there are absolutely more new neurons and new astrocytes in the R6/2 striatum, because there are so many new BrdU-labeled cells in the R6/2 compared with wild-type striatum. Certainly, the increase in astrocytes may reflect the damaged R6/2 striatum. This may result in more astrocytes migrating into the $\mathrm{R} 6 / 2$ striatum. The increased absolute numbers of new neurons in the R6/2 could also reflect a response to damage in the R6/2 striatum but, in addition, could be a consequence of the apparent buildup of migrating neurons in the proximal rostral migratory stream of the R6/2 mice. If these new rostral migratory stream neurons are not migrating correctly to the olfactory bulb, they may be diverted to the striatum (Decker et al., 2002). Buildup of neurons in the rostral migratory stream may not be a sufficient reason for neurons to migrate into the striatum, as demonstrated in NCAM mutant mice (Tomasiewicz et al., 1993). However, in combination with a signal produced in the dysfunctional R6/2 striatum, the buildup of new neurons in the R6/2 rostral migratory stream may produce spillover of the new neurons into the R6/2 striatum.

In conclusion, our findings show, in vitro and in vivo, that $\mathrm{HD}$ adult forebrain exhibits increased numbers of striatal subependymal neural stem cells as a result of cell non-autonomous events, perhaps triggered by changes in the neurochemical environment of the HD striatum. Simultaneously, changes in chemoattractant or chemorepulsive molecules in the HD striatum may encourage the migration of striatal subependymal progenitor cells toward the degenerated striatum in HD. The present data support the notion that adult subependymal precursors can generate progeny that migrate toward injured areas and thus potentially be harnessed for neural repair.

\section{References}

Arvidsson A, Collin T, Kirik D, Kokaia Z, Lindvall O (2002) Neuronal replacement from endogenous precursors in the adult brain after stroke. Nat Med 8:963-970.

Benraiss A, Chmielnicki E, Lerner K, Roh D, Goldman SA (2001) Adenoviral brain-derived neurotrophic factor induces both neostriatal and olfactory neuronal recruitment from endogenous progenitor cells in the adult forebrain. J Neurosci 21:6718-6731.

Calza L, Giardino L, Pozza M, Bettelli C, Micera A, Aloe L (1998) Proliferation and phenotype regulation in the subventricular zone during experimental allergic encephalomyelitis: in vivo evidence of a role for nerve growth factor. Proc Natl Acad Sci USA 95:3209-3214.

Carter RJ, Lione LA, Humby T, Mangiarini L, Mahal A, Bates GP, Dunnett SB, Morton AJ (1999) Characterization of progressive motor deficits in mice transgenic for the human Huntington's disease mutation. J Neurosci 19:3248-3257.

Castano EM, Roher AE, Esh CL, Kokjohn TA, Beach T (2006) Comparative proteomics of cerebrospinal fluid in neuropathologically-confirmed Alzheimer's disease and non-demented elderly subjects. Neurol Res 28:155163.

Chmielnicki E, Benraiss A, Economides AN, Goldman SA (2004) Adenovirally expressed noggin and brain-derived neurotrophic factor cooperate to induce new medium spiny neurons from resident progenitor cells in the adult striatal ventricular zone. J Neurosci 24:2133-2142.

Coggeshall RE, Lekan HA (1996) Methods for determining numbers of cells and synapses: a case for more uniform standards of review. J Comp Neurol 364:6-15.

Craig CG, D'sa R, Morshead CM, Roach A, van der Kooy D (1999) Migrational analysis of the constitutively proliferating subependyma population in adult mouse forebrain. Neuroscience 93:1197-1206.

Curtis MA, Penney EB, Pearson AG, van Roon-Mom WM, Butterworth NJ, Dragunow M, Connor B, Faull RL (2003) Increased cell proliferation and neurogenesis in the adult human Huntington's disease brain. Proc Natl Acad Sci USA 100:9023-9027.

Curtis MA, Penney EB, Pearson J, Dragunow M, Connor B, Faull RL (2005a) The distribution of progenitor cells in the subependymal layer of the lateral ventricle in the normal and Huntington's disease human brain. Neuroscience 132:777-788.

Curtis MA, Waldvogel HJ, Synek B, Faull RLM (2005b) A histochemical and immunohistochemical analysis of the subependymal layer in the normal and Huntington's disease brain. J Chem Neuroanat 30:55-66.

Decker L, Durbec P, Rougon G, Evercooren AB (2002) Loss of polysialic residues accelerates CNS neural precursor differentiation in pathological conditions. Mol Cell Neurosci 19:225-238.

Doetsch F, García-Verdugo JM, Alvarez-Buylla A (1997) Cellular composition and three-dimensional organization of the subventricular germinal zone in the adult mammalian brain. J Neurosci 17:5046-5061.

Gil JM, Leist M, Popovic N, Brundin P, Petersen A (2004) Asialoerythropoietin is not effective in the R6/2 line of Huntington's disease mice. BMC Neurosci 5:17-27.

Hickey MA, Reynolds GP, Morton JA (2002) The role of dopamine in motor symptoms in the R6/2 trangenic mouse model of Huntington's disease. J Neurochem 81:46-59.

Hitoshi S, Tropepe V, Ekker M, van der Kooy D (2002) Neural stem cell lineages are regionally specified, but not committed, within distinct compartments of the developing brain. Development 129:233-244.

Holmin S, Almqvist P, Lendahl U, Mathiesen T (1997) Adult nestin expressing subependymal cells differentiate to astrocytes in response to brain injury. Eur J Neurosci 9:65-75.

Jin K, Minami M, Lan JQ, Mao XO, Batteur S, Simon RP, Greenberg DA (2001) Neurogenesis in dentate subgranular zone and rostral subven- 
tricular zone after focal cerebral ischemia in the rat. Proc Natl Acad Sci USA 98:4710-4715.

Jin N, Chen W, Blazar BR, Ramakrishnan S, Vallera DA (2002) Gene therapy of murine solid tumors with $\mathrm{T}$ cells transduced with a retroviral vascular endothelial growth factor-immunotoxin target gene. Hum Gene Ther 13:497-508.

Kippin TE, Martens DJ, van der Kooy D (2005a) p21 loss compromises the relative quiescence of forebrain stem cell proliferation leading to exhaustion of their proliferation capacity. Genes Dev 19:756-767.

Kippin TE, Kapur S, van der Kooy D (2005b) Dopamine specifically inhibits forebrain neural stem cell proliferation, suggesting a novel effect of antipsychotic drugs. J Neurosci 25:5815-5823.

Kuncl RW, Bilak MM, Bilak SR, Corse AM, Royal W, Becerra SP (2002) Pigment epithelium-derived factor is elevated in CSF of patients with amyotrophic lateral sclerosis. J Neurochem 81:178-184.

Lione LA, Carter RJ, Hunt MJ, Bates GP, Morton AJ, Dunnett SB (1999) Selective discrimination learning impairments in mice expressing the human Huntington's disease mutation. J Neurosci 19:10428-10437.

Lois C, Alvarez-Buylla A (1994) Long-distance neuronal migration in the adult mammalian brain. Science 264:1145-1148.

Luskin MB (1993) Restricted proliferation and migration of postnatally generated neurons derived from the forebrain subventricular zone. Neuron 11:173-189.

Ma L, Morton AJ, Nicholson LF (2003) Microglia density decreases with age in a mouse model of Huntington's disease. Glia 43:274-280.

Mangiarini L, Sathasivam K, Seller M, Cozens B, Harper A, Hetherington C, Lawton M, Trottier Y, Lehrach H, Davies SW, Bates GP (1996) Exon 1 of the HD gene with an expanded CAG repeat is sufficient to cause a progressive neurological phenotype in transgenic mice. Cell 87:493-506.

Morshead CM, van der Kooy D (1992) Postmitotic death is the fate of constitutively proliferating cells in the subependymal layer of the adult mouse brain. J Neurosci 12:249-256.

Morshead CM, Reynolds BA, Craig CG, McBurney MW, Staines WA, Morassutti D, Weiss S, van der Kooy D (1994) Neural stem cells in the adult mammalian forebrain: a relatively quiescent subpopulation of subependymal cells. Neuron 13:1071-1082.

Morshead CM, Craig CG, van der Kooy D (1998) In vivo clonal analyses reveal the properties of endogenous neural stem cell proliferation in the adult mammalian forebrain. Development 125:2251-2261.

Morshead CM, Benveniste P, Iscove NN, van der Kooy D (2002) Hematopoietic competence is a rare property of neural stem cells that may depend on genetic and epigenetic alterations. Nat Med 8:268-273.

Morshead CM, Garcia AD, Sofroniew MV, van Der Kooy D (2003) The ablation of glial fibrillary acidic protein-positive cells from the adult central nervous system results in the loss of forebrain neural stem cells but not retinal stem cells. Eur J Neurosci 18:76-84.

Palmer TD, Willhoite AR, Gage FH (2000) Vascular niche for adult hippocampal neurogenesis. J Comp Neurol 425:479-494.

Parent JM, Valentin VV, Lowenstein DH (2002) Prolonged seizures increase proliferating neuroblasts in the adult rat subventricular zoneolfactory bulb pathway. J Neurosci 22:3174-3188.

Petersen A, Puschban Z, Lotharius J, NicNiocaill B, Wiekop P, O’Connor
WT, Brundin P (2002) Evidence for dysfunction of the nigrostrital pathway in the R6/1 line of transgenic Huntington's disease mice. Neurobiol Dis 11:134-146.

Phillips W, Morton AJ, Barker RA (2005) Abnormalities of neurogenesis in the R6/2 mouse model of Huntington's disease are attributable to the in vivo microenvironment. J Neurosci 25:11564-11576.

Pineda JR, Canals JM, Bosch M, Adell A, Mengod G, Artigas F, Ernfors P, Alberch J (2005) Brain-derived neurotrophic factor modulates dopaminergic deficits in a transgenic model of Huntington's disease. J Neurochem 93:1057-1068.

Ramírez-Castillejo C, Sanchez-Sanchez F, Andreu-Agullo C, Ferron SR, Aroca-Aguilar JD, Sanchez P, Mira H, Escribano J, Farinas I (2006) Pigment epithelium-derived factor is a niche signal for neural stem cell renewal. Nat Neurosci 9:331-339.

Reynolds BA, Weiss S (1992) Generation of neurons and astrocytes from isolated cells of the adult mammalian central nervous system. Science 255:1707-1710

Reynolds BA, Weiss S (1996) Clonal and population analyses demonstrate that an EGF-responsive mammalian embryonic CNS precursor is a stem cell. Dev Biol 175:1-13.

Sathasivam K, Hobbs C, Mangiarini L, Amarbirpal M, Turmaine M, Doherty P, Davies SW, Bates GP (1999) Transgenic models in Huntington's disease. Philos Trans R Soc Lond B Biol Sci 354:963-969.

Saudou F, Finkbeiner S, Devys D, Greenberg ME (1998) Huntingtin acts in the nucleus to induce apoptosis but death does not correlate with the formation of intranuclear inclusions. Cell 95:55-66.

Seaberg RM, van der Kooy D (2003) Stem and progenitor cells: the premature desertion of rigorous definitions. Trends Neurosci 26:125-131.

The Huntington's Disease Collaborative Research Group (1993) A novel gene containing a trinucleotide repeat that is expanded and unstable on Huntington's disease chromosomes. Cell 72:971-983.

Tomasiewicz H, Ono K, Yee D, Thompson C, Goridis C, Rutishauser U, Magnuson T (1993) Genetic deletion of a neural cell adhesion molecule variant (N-CAM-180) produces distinct defects in the central nervous system. Neuron 11:1163-1174.

Tropepe V, Sibilia M, Ciruna BG, Rossant J, Wagner EF, van der Kooy D (1999) Distinct neural stem cells proliferate in response to EGF and FGF in the developing mouse telencephalon. Dev Biol 208:166-188.

Weiss S, Reynolds BA, Vescovi AL, Morshead C, Craig CG, van der Kooy D (1996) Is there a neural stem cell in the mammalian forebrain? Trends Neurosci 19:387-393.

Zhang SX, Wang JJ, Gao G, Shao C, Mott R, Ma JX (2006) Pigment epithelium-derived factor (PEDF) is an endogenous antiinflammatory factor. FASEB J 20:323-325.

Zigova T, Pencea V, Wiegand SJ, Luskin MB (1998) Intraventricular administration of BDNF increases the number of newly generated neurons in the adult olfactory bulb. Mol Cell Neurosci 11:234-245.

Zuccato C, Liber D, Ramos C, Tarditi A, Rigamonti D, Tartari M, Valenza M, Cattaneo E (2005) Progressive loss of BDNF in a mouse model of Huntington's disease and rescue by BDNF delivery. Pharmacol Res 52:133139. 